\title{
Effects of MDMA and Intranasal Oxytocin on Social and Emotional Processing
}

\author{
Matthew G Kirkpatrick', Royce Lee', Margaret C Wardle', Suma Jacob ${ }^{2}$ and Harriet de Wit*,' \\ 'Department of Psychiatry and Behavioral Neurosciences, University of Chicago, Chicago, IL, USA; '2Department of Psychiatry, University of \\ Minnesota, Chicago, IL, USA
}

\begin{abstract}
MDMA ( $\pm 3,4$-methylenedioxymethamphetamine, 'ecstasy') is used recreationally, reportedly because it increases feelings of empathy, sociability, and interpersonal closeness. One line of evidence suggests that MDMA produces these effects by releasing oxytocin, a peptide involved in social bonding. In the current study, we investigated the acute effects of MDMA and oxytocin on social and emotional processing in healthy human volunteers. MDMA users $(N=65)$ participated in a 4-session, within-between-subjects study in which they received oral MDMA $(0.75,1.5 \mathrm{mg} / \mathrm{kg}$ ), intranasal oxytocin $(20$ or $40 \mathrm{lU})$, or placebo under double-blind conditions. The primary outcomes included measures of emotion recognition and sociability (desire to be with others). Cardiovascular and subjective effects were also assessed. As expected, MDMA dose-dependently increased heart rate and blood pressure and feelings of euphoria (eg, 'High' and 'Like Drug'). On measures of social function, MDMA impaired recognition of angry and fearful facial expressions, and the larger dose $(1.5 \mathrm{mg} / \mathrm{kg})$ increased desire to be with others, compared with placebo. Oxytocin produced small but significant increases in feelings of sociability and enhanced recognition of sad facial expressions. Additionally, responses to oxytocin were related to responses to MDMA with subjects on two subjective measures of sociability. Thus, MDMA increased euphoria and feelings of sociability, perhaps by reducing sensitivity to subtle signs of negative emotions in others. The present findings provide only limited support for the idea that oxytocin produces the prosocial effects of MDMA.

Neuropsychopharmacology (2014) 39, I654-1663; doi:I0.1038/npp.2014.12; published online I2 February 2014
\end{abstract}

Keywords: MDMA; oxytocin; mood; social behavior; emotion; humans

\section{INTRODUCTION}

The amphetamine analog 3,4-methylenedioxymethamphetamine (MDMA, 'ecstasy') is a common recreational drug, typically used in social settings and reportedly used because it produces feelings of empathy, sociability, and interpersonal closeness (Bravo, 2001; Kelly et al, 2006; Rodgers et al, 2006; Sumnall et al, 2006). In light of these effects, it is also being tested as an adjunct to psychotherapy for post traumatic stress disorder (Mithoefer et al, 2013). Yet, the mechanisms by which MDMA produces its apparently unique empathogenic effects are not known. One line of evidence suggests that MDMA produces these effects by releasing oxytocin, a peptide involved in social bonding (Bos et al, 2011). Oxytocin has also been linked to drug abuse in other contexts: Burkett and Young (2012) point to striking resemblances between addiction and social bonding and attachment, noting substantial overlap between the endogenous oxytocin and drug reward systems,

*Correspondence: Dr $\mathrm{H}$ de Wit, Department of Psychiatry and Behavioral Neuroscience, MC 3077, University of Chicago, 584I South Maryland Avenue, Chicago, IL 60637, USA, Tel: +I 773702 5855, Fax: + 773834 7698, E-mail: hdew@uchicago.edu

Received 3 July 2013; revised II January 2014; accepted I5 January 20I4; accepted article preview online 22 January 2014 and McGregor and Bowen (2012) have proposed that oxytocin may be a safe and effective treatment for drug addiction. Together, these links suggest that there may be commonalities in the prosocial subjective, cognitive, and behavioral effects of MDMA and oxytocin.

In the human laboratory, MDMA enhances subjective, cognitive, and emotional measures of social processing. It increases positive mood states, as well as feelings of friendliness and feeling close to others (Bedi et al, 2010; Harris et al, 2002; Hysek and Liechti, 2012; Kirkpatrick et al, 2012; Tancer and Johanson, 2003). On objective measures of social function, it alters the ability to recognize the emotions of others: it improves correct categorization of positive mental states, such as friendliness in others (Hysek et al, 2012) while impairing categorization of negative states such as expressions of hostility or fear (Bedi et al, 2010; Hysek et al, 2012). Thus, MDMA may facilitate social behavior by producing positive and prosocial subjective states, as well as by enhancing the sensitivity to positive emotions and reducing sensitivity to negative emotions in others.

MDMA may produce these effects in part by increasing release of oxytocin. In addition to its effects on dopamine, serotonin, and norepinephrine in the brain (Han and $\mathrm{Gu}$, 2006; Rothman et al, 2001; Verrico et al, 2007), MDMA also appears to release oxytocin. In rats, MDMA increases oxytocin levels in the brain, and oxytocin receptor 
antagonists attenuate the behavioral effects of MDMA (Thompson et al, 2007). In humans, MDMA increases plasma levels of oxytocin (Dumont et al, 2009; Hysek et al, 2012), and these increases are correlated with feelings of sociability (Dumont et al, 2009). Single doses of intranasal oxytocin can also produce prosocial, anxiolytic, and affiliative effects in healthy adults (Bos et al, 2011; Lim and Young, 2006). For example, oxytocin has been shown to increase trust and generosity (Kosfeld et al, 2005; Zak et al, 2007), reduce responses to social stressors (Heinrichs et al, 2003), increase positive communication (Ditzen et al, 2009), and, like MDMA, enhance recognition of positive emotional states and dampen responses to negative emotions in others ( $\mathrm{Di}$ Simplicio et al, 2009; Domes et al, 2007a,b; Marsh et al, 2010; Shahrestani et al, 2013). On the other hand, other studies have failed to detect prosocial effects of oxytocin, and indeed, found that it can produce antisocial effects such as feelings of envy and mistrust (Bartz et al, 2011a; Declerck et al, 2010; Shamay-Tsoory et al, 2009). The conditions under which oxytocin enhances, or impairs, social interaction remain to be determined. Nevertheless, similar patterns of prosocial effects produced by MDMA and intranasal oxytocin would be consistent with the possibility that central oxytocin contributes to the prosocial effects of MDMA. To examine this possibility, we examined the prosocial effects of both MDMA and oxytocin in the same individuals.

In this study, we tested the subjective, cardiovascular, and behavioral effects of oral MDMA (0.75 and $1.5 \mathrm{mg} / \mathrm{kg}$ ) and intranasal oxytocin (20 and $40 \mathrm{IU}$ ) in healthy young adults, using a mixed between- and within-subjects design. We assessed the drugs' effects on both self-reported and objective indices of social and emotional processing, including mood states, feelings of sociability, recognition of facial emotion, and desire to socialize. We hypothesized that both MDMA and oxytocin would dose-dependently (1) increase self-report measures of sociability and desire to socialize and (2) enhance objective indicators of social function. Previous data from our laboratory and others indicate that MDMA dose-dependently increases both cardiovascular measures and feelings of euphoria, whereas intranasal oxytocin does not (Bedi et al, 2009, 2010; de Oliveira et al, 2012; Norman et al, 2011; MacDonald and MacDonald, 2010). Therefore, we further predicted that only MDMA would increase self-reported 'positive' mood as well as heart rate and blood pressure. We tested enough subjects to examine relationships between subjects' subjective responses to MDMA and oxytocin.

\section{MATERIALS AND METHODS}

\section{Participants}

Healthy men and women $(N=65 ; 25$ female, 40 male) with light-to-moderate past MDMA experience (ie, 4-40 times in their lifetime) were recruited via newspaper, community bulletin board, and online advertisements. Potential participants completed an initial telephone and an in-person psychiatric evaluation and medical examination, including an electrocardiogram and a physical examination. Inclusion criteria were age between 18 and 35 years, at least a high school education, fluency in English, and BMI between 18 and 30. All participants were Caucasian because this was part of a larger genetic study. Exclusion criteria included smoking $>10$ cigarettes per day, night shift work, any significant medical or psychiatric condition (eg, cardiovascular, neurological, or major psychiatric illness including all Axis I disorders) or any other condition that would increase risk for study participation (such as sinus infection or other condition blocking access to the olfactory epithelium).

Participants were told that the purpose of the study was to evaluate individual differences in drug response. They were told they could receive a stimulant (such as amphetamine or ecstasy), a sedative (such as Valium), a cannabinoid, a hormone (such as oxytocin), or a placebo. Participants were instructed to consume their normal amount of caffeine, but were asked to refrain from tobacco use for $9 \mathrm{~h}$, and other drug use for $48 \mathrm{~h}$, before each session. Women who used hormonal contraceptives were tested regardless of menstrual cycle phase, but women not using hormonal contraceptives were tested only during the follicular phase (days 2-14; White et al, 2002). The study was approved by the Institutional Review Board at the University of Chicago in accordance with the Code of Federal Regulations (Title 45, Part 46) adopted by the National Institutes of Health and the Office for Protection from Research Risks of the US Federal Government. Participants provided written informed consent before participation and after completing all sessions they were debriefed to explain the study.

\section{Design}

The study used a within-and-between-subjects, doubledummy design in which subjects received two doses of MDMA ( 0.75 and $1.5 \mathrm{mg} / \mathrm{kg}$ ), one dose of oxytocin (20 or $40 \mathrm{IU}$ ), and placebo (Table 1). After an initial orientation session, participants completed four outpatient sessions separated by at least 5 days as a washout period (Abraham et al, 2009). Dosing order was randomized. On each session, participants ingested a capsule (placebo or MDMA) and received a nasal spray (placebo or oxytocin). Their mood states and physiological measures were monitored at baseline and for $4 \mathrm{~h}$ after drug administration.

\section{Procedure}

Sessions were conducted between 0900 and $1330 \mathrm{~h}$. Upon reporting to the laboratory, participants provided urine and breath samples to confirm abstinence from alcohol (as measured by an Alco-Sensor III Breathalyzer, Intoximeters, St Louis, MO), amphetamine, cocaine, and opiates

Table I Study Design

\begin{tabular}{lllll}
\hline & Session I & Session 2 & Session 3 & Session 4 \\
\hline Capsule & Placebo & Placebo & $\begin{array}{l}0.75 \mathrm{mg} / \mathrm{kg} \\
\mathrm{MDMA}\end{array}$ & $\begin{array}{l}1.5 \mathrm{mg} / \mathrm{kg} \\
\mathrm{MDMA}\end{array}$ \\
$\begin{array}{llll}\text { Intranasal spray } \\
\text { Placebo }\end{array}$ & $\begin{array}{l}\text { 20 or 40 IU } \\
\text { Oxytocin }\end{array}$ & $\begin{array}{l}\text { Placebo } \\
\text { Placebo }\end{array}$ & \\
& & &
\end{tabular}

The order of drugs was randomized across subjects. All participants received both doses of MDMA and placebo, and one active oxytocin dose (20 IU $(N=43)$ or $40 ॥(N=22))$ 
(as measured by urine toxicology: Ontrak TesTstik, Roche Diagnostic Systems, Somerville, NJ), and marijuana (as measured by a saliva test: Oratect, Branan Medical Corp., Irvine, CA), and women were tested for pregnancy. Sessions were rescheduled if the participant tested positive for drugs.

At $0920 \mathrm{~h}$, baseline (pre-capsule) measures of heart rate and blood pressure were obtained, and participants completed self-report mood and drug effect questionnaires (see below). At $0930 \mathrm{~h}$, participants ingested capsules containing either MDMA or placebo. At $0955 \mathrm{~h}$ physiological and subjective measures were obtained and at $1000 \mathrm{~h}$ they received an intranasal spray containing either oxytocin or placebo (see below). Forty-three participants received 20 IU oxytocin and 22 participants received $40 \mathrm{IU}$. Physiological and subjective measures were obtained at 1030, 1100, 1130, 1300, and $1330 \mathrm{~h}$. Behavioral tasks were completed between 1030 and $1200 \mathrm{~h}$ (described below). During times when no measures were scheduled the participants were allowed to relax and watch movies or read. At $1330 \mathrm{~h}$, they completed the end of session questionnaire (ESQ: see below), and were discharged provided that their heart rate and blood pressure had returned to baseline levels.

\section{Physiological Measures}

Heart rate and blood pressure were measured at regular intervals throughout the sessions using portable monitors (Life Source, A\&D, Tokyo, Japan).

\section{Subjective Effects and ESQ}

Participants completed subjective-effect questionnaires before and at regular intervals after capsule and nasal spray administration. The drug-effect questionnaire (DEQ) is a visual analog questionnaire designed to assess the extent to which participants experienced the effects of the drugs: 'Feel Drug', 'Feel High', 'Like Drug', 'Dislike Drug', and 'Want More' (Fischman and Foltin, 1991; Justice and De Wit, 2000). Each item was presented with a $100-\mathrm{mm}$ line labeled 'not at all' at one end and 'extremely' at the other end. They also completed a series of visual analog scales (VAS: $0-$ $100 \mathrm{~mm}$; not at all to extremely) that consisted of adjectives describing several MDMA-related mood effects (ie, 'I feel...' 'Anxious,' 'Dizzy,' 'Elated,' 'Restless,' 'Sedated,' and 'Stimulated') and 'prosocial' effects (ie, 'I feel...,' 'Confident,' 'Friendly,' 'Insightful,' 'Loving', 'Lonely,' 'Playful,' and 'Sociable'). At the end of the sessions, participants completed the ESQ on which they rated how much they would like to take the drug again (VAS: 0-100).

\section{Behavioral Measures}

Computerized social and emotional processing tasks. Participants completed two computerized measures of social and emotional processing, between 10:30 and 11:30 am during the anticipated time of peak drug effects. The order of task presentation was randomized.

The first task was the Morphed Facial Expression Task (mFER), which employs standardized faces taken from the Pictures of Facial Affect set (Ekman and Friesen, 1976), morphed by $10 \%$ increments between $0 \%$ emotional expression (ie, a neutral face) and $100 \%$ emotional expression
(Young et al, 1997). The version of the task includes four basic emotions (ie, anger, fear, happiness, and sadness). Faces were presented in a randomized order for $500 \mathrm{~ms}$ and participants selected the emotion depicted. The outcome measure was accuracy (defined as the proportion of correct identifications minus the proportion of false alarms).

Participants also completed the Social Evaluation Task (SET) during which they rated the perceived attractiveness, friendliness, and trustworthiness of facial pictures. Stimuli consisted of 80 full color faces; 20 different faces were presented each session (10 male and 10 female aged 18-25 years; Jones et al, 2003). Participants rated each image on a 7-point Likert scale (eg, 'very unattractive' to 'very attractive'). Outcome measures were mean attractiveness, friendliness, and trustworthiness ratings, analyzed separately based on the gender of the participant and the facial image.

Social Choice Task. At noon $(2.5 \mathrm{~h}$ after ingesting the capsule), participants were asked to rate their desire to engage in three 10-min activities: a social activity (ie, chatting with another person) and two solitary activities (ie, solving word problems or sitting quietly by themselves) on a Likert scale (1-10). Participants were instructed that their ratings, combined with an element of chance, would determine which activity was selected. In fact, the outcome of this task was randomized and determined before study participation. Subjects then engaged in the selected activity; for the social activity, they interacted with a trained confederate.

\section{Drugs}

Drug conditions were administered in randomized order, under double-blind conditions. Capsules and nasal sprays were prepared by The University of Chicago Hospitals investigational pharmacy. MDMA powder $(0.75$ and $1.5 \mathrm{mg} / \mathrm{kg}$ ) was encapsulated in 00 opaque capsules with lactose filler. Placebo capsules contained only lactose. These MDMA doses were selected based on our previous studies indicating that the drug reliably increases positive mood and alters emotional processing at these doses (Bedi $e t$ al, 2009,2010 ). Intranasal oxytocin (20 and $40 \mathrm{IU}$ ) doses were prepared within $24 \mathrm{~h}$ of use. A single dose of Pitocin (OT Injection USB; Monarch Pharmaceuticals; concentration: 10 or $20 \mathrm{IU}$ Pitocin/ $1 \mathrm{ml}$ ) was transferred into two, $1 \mathrm{ml}$ intranasal atomizers (MAD300 by LMA, San Diego, CA). Placebo nasal sprays consisted of Ocean Spray Nasal Solution (Valeant Pharmaceuticals, Bridgewater, NJ). The doses of 20 and $40 \mathrm{IU}$ oxytocin were chosen based on previous studies utilizing intranasally administered oxytocin and vasopressin (Bos et al, 2011; MacDonald et al, 2011). Nasal sprays were administered by a trained personnel in four doses to each nare over the course of 15 min. During the administration, participants sat comfortably in reclined position, with their heads tilted back to maximize absorption.

\section{Data Analysis}

Acute MDMA-related effects. Data from the placebo and active MDMA sessions were analyzed using multilevel linear models (MLMs). Independent (fixed) effects were drug 
(placebo, 0.75 and $1.5 \mathrm{mg} / \mathrm{kg}$ MDMA), sex, and session order. For cardiovascular and subjective-effects measures, time of assessment was included as an independent factor. MLMs provided the error terms needed to calculate the following within-subjects planned comparisons: (1) placebo vs both active MDMA doses and (2) 0.75 vs $1.5 \mathrm{mg} / \mathrm{kg}$ MDMA.

Acute oxytocin-related effects. Data from the placebo and active oxytocin sessions were analyzed using MLMs. Independent (fixed) effects were drug (placebo and oxytocin), group (20 and $40 \mathrm{IU}$ oxytocin), sex, and session order. For cardiovascular and subjective-effects measures, time of assessment was included as an independent factor. MLMs provided the error terms needed to calculate both within- and between-subjects comparisons: (1) placebo vs oxytocin and (2) $20 \mathrm{IU}$ group vs $40 \mathrm{IU}$ group. We checked to ensure that the subjects receiving 20 or 40 IU did not differ on key demographic variables, including sex, age, education, BMI, MDMA use, or current use of other drugs.

Correlations between MDMA- and oxytocin-related prosocial subjective effects. We conducted secondary partial correlational analyses to investigate the relationship between subjective responses to MDMA and oxytocin. To summarize subjective effects across the entire session, we calculated area-under-the-curve (AUC) for each prosocial subjective item, relative to the participant's pre-drug baseline, using the trapezoidal method (Tallarida and Murray, 1981). For each group (20 and 40 IU oxytocin), ratings from the oxytocin session were compared with ratings from MDMA sessions while controlling for placebo session ratings.

For all analyses and comparisons, $P$-values were considered as statistically significant at $<0.05$.

\section{RESULTS}

\section{Sample Characteristics}

In total, 65 volunteers ( $38 \%$ female) completed the study. They were $23.8 \pm 3.9$ (mean $\pm \mathrm{SD}$ ) years old and had completed $14.6 \pm 1.4$ years of formal education. They had used MDMA a mean of $15.0 \pm 11.2$ times (range 4-40 lifetime). Table 2 provides additional demographic information for participants who received 20 or $40 \mathrm{IU}$ oxytocin. The participants did not differ on any demographic measure.

\section{MDMA-Related Effects}

Physiological effects. MDMA dose-dependently increased cardiovascular measures across the session (Figure 1). Both doses significantly increased heart rate, systolic pressure, and diastolic pressure compared with placebo $(F[2$, $1300]=114.9-230.9, P<0.001)$, and the larger dose produced a greater cardiovascular response compared with the lower dose $(P<0.001$ for all comparisons). Peak cardiovascular effects occurred between 90 and $120 \mathrm{~min}$.

Subjective effects and ESQ. MDMA produced robust increases in self-reported ratings of feeling the drug. The drug increased ratings of both liking and disliking and it
Table 2 Demographics of Participants Who Received 20 or $40 \mathrm{IU}$ Oxytocin

\begin{tabular}{|c|c|c|c|c|}
\hline & \multicolumn{4}{|c|}{ Group } \\
\hline & \multicolumn{2}{|c|}{$\begin{array}{c}20 \mathrm{IU} \\
(\mathrm{N}=\mathrm{I} 5 \mathrm{~F} ; 28 \mathrm{M})\end{array}$} & \multicolumn{2}{|c|}{$\begin{array}{c}40 \mathrm{IU} \\
(\mathrm{N}=10 \mathrm{~F} ; \mathrm{I} \mathrm{M})\end{array}$} \\
\hline & Mean & SD & Mean & SD \\
\hline Age (years) & 24.1 & 4.1 & 23.1 & 3.5 \\
\hline Education (years) & 14.7 & 1.4 & 14.4 & 1.3 \\
\hline BMI & 23.1 & 2.9 & 22.4 & 2.3 \\
\hline MDMA use (lifetime) & 13.5 & 10.6 & 18.1 & 12.0 \\
\hline Last MDMA use (months) & 21.7 & 35.9 & 10.9 & 10.7 \\
\hline \multicolumn{5}{|l|}{ Current drug use } \\
\hline Alcohol (drinks/week) & 3.7 & 3.2 & 4.2 & 2.0 \\
\hline Caffeine (cups/day) & 1.6 & 1.3 & 2.3 & 2.3 \\
\hline Marijuana (days/month) & 7.7 & 8.4 & 11.4 & 10.1 \\
\hline Tobacco (cigarettes/day) & 2.6 & 4.7 & 3.1 & 3.7 \\
\hline
\end{tabular}

The groups did not differ on any neasure

increased both positive mood states such as elated and friendly and negative states such as anxious and lonely (Table 3; Figure 2, top panels). Relative to placebo, both doses increased ratings of 'Feel Drug,' 'Friendly,' and 'Insightful' (Figure 2, $F[2,1300]=74.7-323.4, P<0.001$ ) and these effects were greater with the higher dose $(P<0.001$ for all comparisons). The drug's effects on all subjective ratings peaked $60-120 \mathrm{~min}$ after capsule ingestion. On the ESQ, MDMA dose-dependently increased selfreported desire to take the drug again (Table $3, F[2$, $130]=22.1, P<0.001)$.

Computerized social and emotional processing tasks. On the mFER task, the higher dose of MDMA significantly reduced accuracy in identifying Angry and Fearful faces $(F[2,128]=5.1, \quad P<0.01$ for both facial expressions $)$, whereas neither dose significantly affected identification of happy or sad faces (Figure 3). MDMA did not alter ratings on the SET.

Social Choice Task. After the larger dose of MDMA, participants were more likely to rate socializing as more desirable, while the desire for solitary activities was unaffected (Figure $4 ; P<0.05$ ).

\section{Oxytocin-Related Effects}

Physiological effects. Neither dose of oxytocin (20 or $40 \mathrm{IU})$ affected heart rate or blood pressure compared with placebo (Supplementary Table 1).

Subjective effects and ESQ. Oxytocin increased several self-report measures, compared with placebo, but these effects were small compared with the effects of MDMA. Both doses increased ratings of 'Friendly' and 'Elated' compared 
Heart Rate

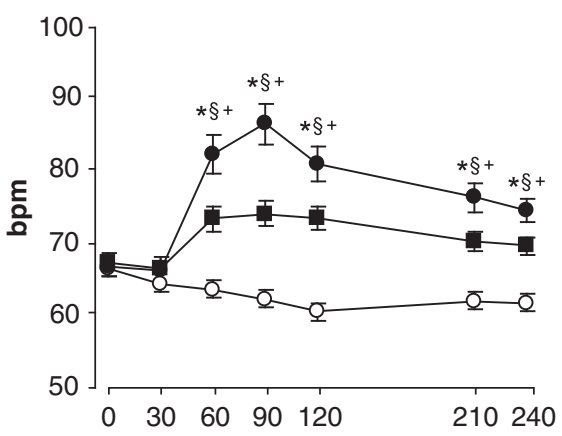

Systolic Pressure

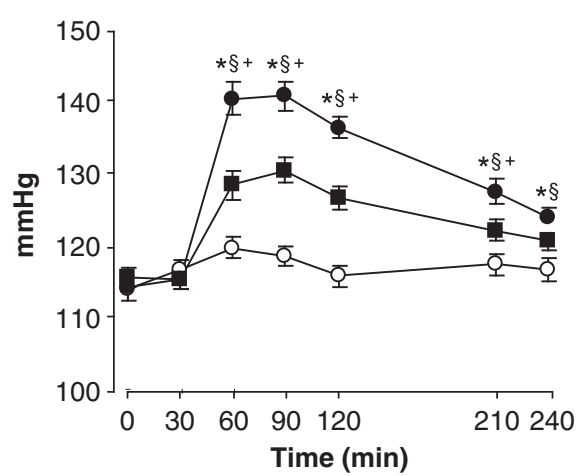

Diastolic Pressure

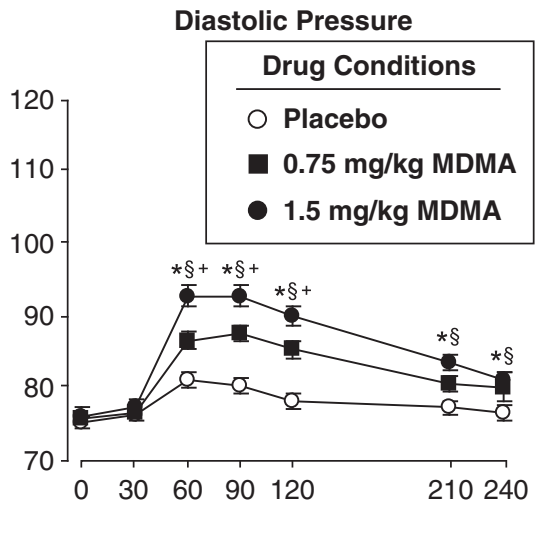

Figure I Mean (SEM) heart rate and blood pressure following administration of MDMA or placebo as a function of dose and time. An * indicates $1.5 \mathrm{mg} / \mathrm{kg}$ MDMA significantly different from placebo $(P<0.05)$. A $\S$ indicates $0.75 \mathrm{mg} / \mathrm{kg}$ MDMA significantly different from placebo $(P<0.05)$. $A+$ indicates $1.5 \mathrm{mg} / \mathrm{kg}$ significantly different from $0.75 \mathrm{mg} / \mathrm{kg}$ MDMA $(P<0.05)$. Error bars represent SEM. Overlapping error bars were omitted for clarity.

with placebo (Figure 2, bottom middle panel, some data not shown; $F[1,845]=7.6-20.2, P<0.01)$. Over time, only the lower dose increased ratings of 'Insightful' (Figure 2, bottom right panel) and 'Social,' and decreased ratings of 'Anxious' (data not shown; $F[1,845]=5.9-45.6, P<0.05$ ). On the ESQ, only the $40 \mathrm{IU}$ dose increased self-reported desire to take the drug again $(F[1,66]=7.1, P<0.01)$. Mean ratings over the course of the entire session for all selfreport measures are provided in Supplementary Table 1.

Computerized social and emotional processing tasks. The 40-IU oxytocin dose improved identification of sad faces, only in women (placebo $=0.49 \pm 0.04$ vs oxytocin $=$ $0.59 \pm 0.04: F[1,64]=8.6, P<0.01)$. Neither dose of oxytocin affected identification of other emotions, or performance on the SET.

Social Choice Task. Neither oxytocin dose altered ratings on the Social Choice Task.

\section{Correlations between MDMA- and Oxytocin-Related Prosocial Subjective Effects}

Subjective response to the lower oxytocin dose was significantly correlated with MDMA subjective response on some prosocial measures. Ratings of 'Insightful' after $20 \mathrm{IU}$ oxytocin were positively correlated with ratings on this measure after MDMA $(r=0.38$ and 0.37 , for the lower and larger MDMA dose, respectively). Similarly, ratings of 'Playful' after oxytocin (20 IU) were positively correlated with ratings on this measure after MDMA $(1.5 \mathrm{mg} / \mathrm{kg}$ : $r=0.31$ ). However, subjective responses after 40 IU oxytocin were not related to MDMA responses, suggesting that the 20-IU oxytocin-MDMA correlations may have been spurious (Supplementary Table 2).

\section{DISCUSSION}

The current results confirm and extend previous reports on the prosocial effects of MDMA and intranasal oxytocin. MDMA dose-dependently increased subjective feelings of friendliness and sociability and the larger dose $(1.5 \mathrm{mg} / \mathrm{kg})$ increased desire to socialize with others. Additionally, the larger MDMA dose decreased recognition of negative emotional faces, supporting previous evidence that the drug's prosocial behavioral effects might be partially explained by a decreased capacity to perceive negative emotional states in others. Intranasal oxytocin produced small increases in selfreported sociability but, in contrast to MDMA, oxytocin (40 IU) enhanced recognition of negative emotional faces, suggesting that MDMA- and oxytocin-related effects are not synonymous. Overall, these data are consistent with previous reports of the prosocial effects of MDMA (Bedi et al, 2009, 2010; Hysek et al, 2012; Hysek and Liechti, 2012; Kirkpatrick et al, 2012; Tancer and Johanson, 2003) and extend these earlier findings by demonstrating modest correlations between the effects of MDMA and oxytocin in the same individuals.

MDMA dose-dependently increased subjective ratings of sociability and 'positive' mood. The drug increased ratings of drug liking as well as feelings of friendliness, insightful, and sociable. Interestingly, the drug also increased several 'negative' subjective ratings such as drug disliking, and feelings of anxiety and loneliness. Overall, these subjective data are consistent with other studies indicating that MDMA produces both 'positive' and 'negative' mood states under controlled laboratory conditions (Bedi et al, 2009, 2010; Hysek and Liechti, 2012; Kirkpatrick et al, 2012; Tancer and Johanson, 2003). This mixed profile of both positive and negative subjective effects is consistent with the purportedly low abuse potential of MDMA relative to other amphetamines (Kirkpatrick et al, 2012). It is possible that some of the negative subjective effects (eg, increased loneliness) were related to the socially isolated testing conditions, and these effects might not be evident in a social context (Doty and de Wit, 1995; Kirkpatrick and de Wit, 2013). Interestingly, in our study MDMA also increased a behavioral measure of preference for social activities. When subjects were asked to rate their desire to engage in social and non-social activities, they reported increased desire for the social activity after MDMA $(1.5 \mathrm{mg} / \mathrm{kg})$. While similar effects have been shown for amphetamine (Higgins and Stitzer, 1988), this is the first time that MDMA has been 
Table 3 MDMA-Related Mean (SEM) Self-Report Ratings Over the Entire Session, Calculated as Change from Pre-Capsule (Except End-of-Session)

Drug condition

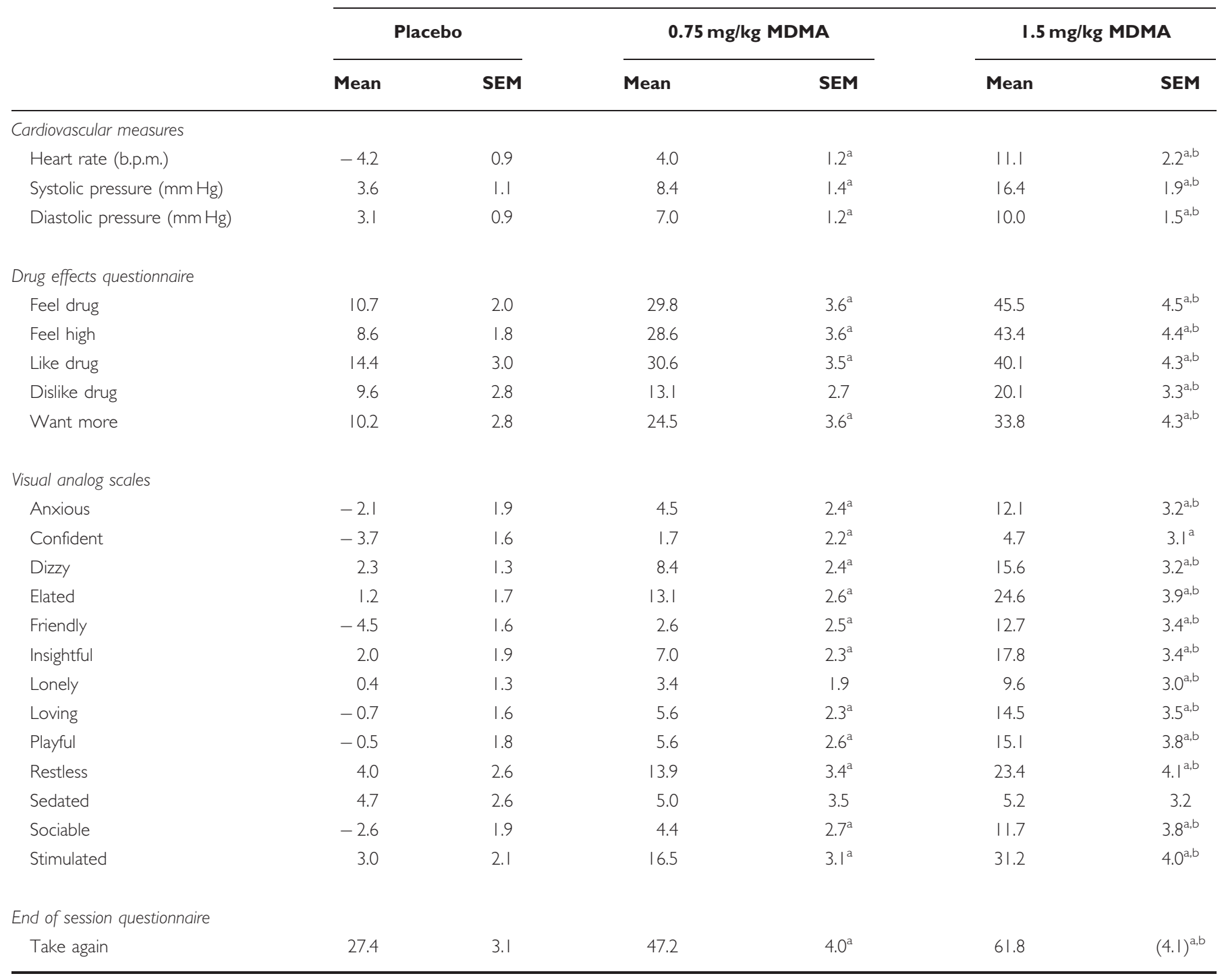

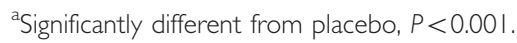

${ }^{\mathrm{b}}$ Significantly different from $0.75 \mathrm{mg} / \mathrm{kg}, P<0.00 \mathrm{I}$.

found to affect preference for social activity. Overall, these data suggest that MDMA-related subjective effects may be enhanced if the drug was administered in the presence of other individuals. Future studies might directly compare acute MDMA-related effects in a social $v s$ an isolated context.

MDMA $(1.5 \mathrm{mg} / \mathrm{kg})$ impaired recognition of negative facial expressions (ie, angry and fearful), without affecting recognition of happy faces. This is consistent with some findings (Bedi et al, 2010), although in other studies MDMA also improved identification of positive emotions using a different task (Reading the Eyes in the Mind Task, which shows only the area around the eyes: Hysek et al, 2012). The current study also differs from past findings by measuring accuracy in a way that controls for false alarms. Nonetheless, the extent to which MDMA increases social behavior by decreasing sensitivity to negative expressions or increasing sensitivity to positive expressions remains to be resolved. In a recent study, patients receiving MDMAassisted treatment for PTSD (Mithoefer et al, 2013) reported an increased ability to focus on negative emotions. However, the nature of the MDMA effect remains unclear. In the present study, MDMA did not alter performance on the other measure of social and emotional processing (ie, perception of attractiveness and trustworthiness). The exact behavioral and psychological processes involved in the prosocial effects of this drug remain to be determined, perhaps by testing subjects under more naturalistic social conditions, or using more sensitive probes, including psychophysiological measures (Wardle and de Wit, 2012).

Intranasal oxytocin also increased subjective feelings of sociability and some measures of positive mood. Both doses of intranasal oxytocin increased ratings of 'Friendly' and 'Elated,' and the lower oxytocin dose (20 IU) also increased 
Feel Drug
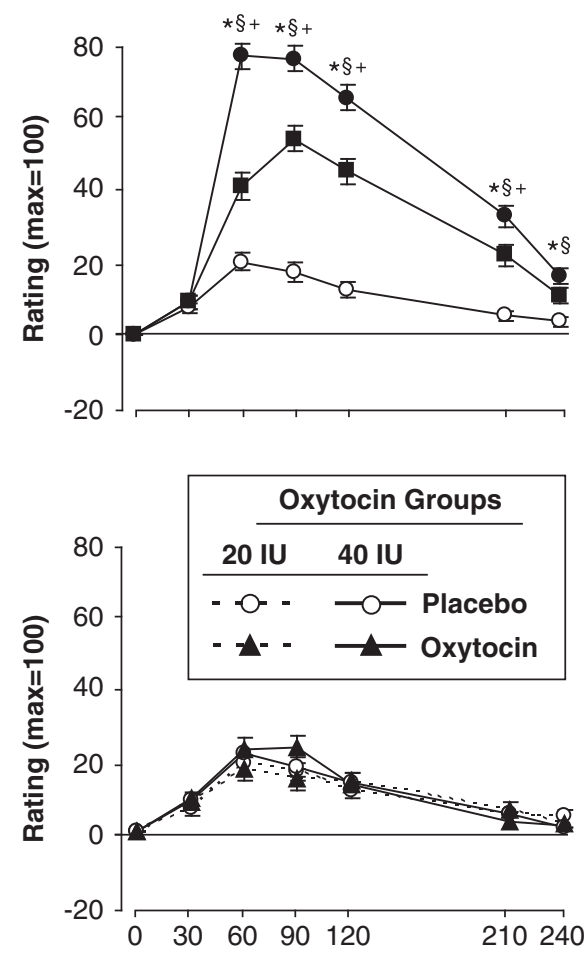

Friendly
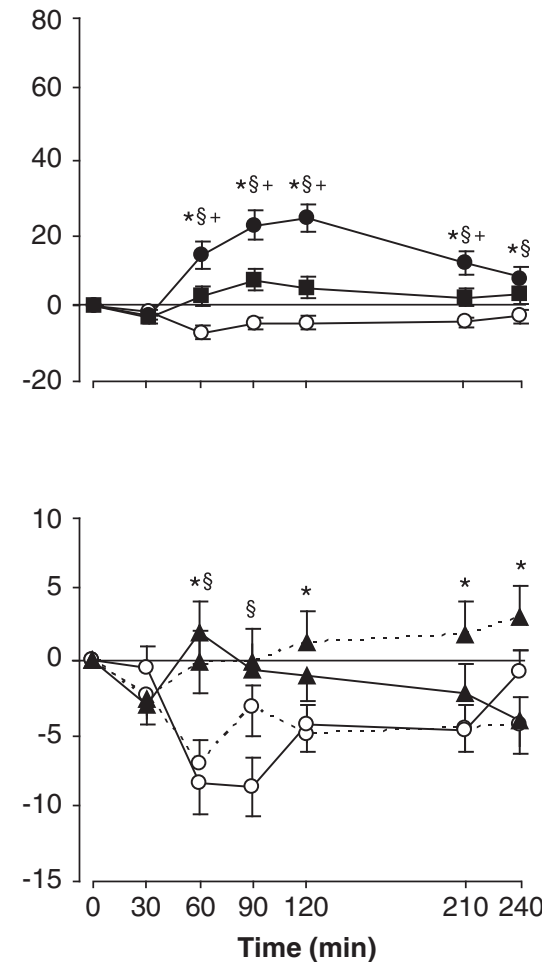

Insightful

MDMA Drug Conditions
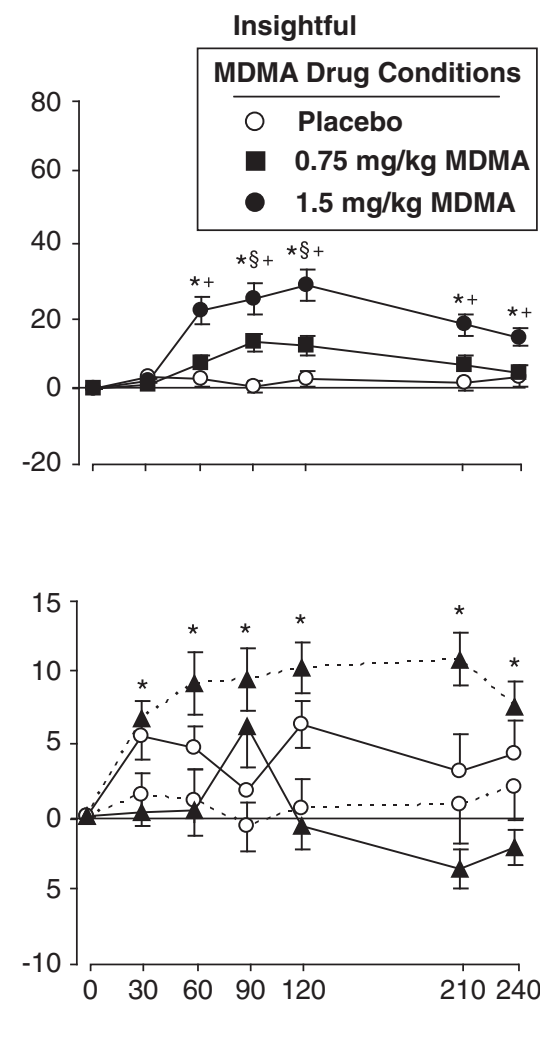

Figure 2 Top panels: Selected mean scores on subjective ratings following administration of MDMA or placebo as a function of dose and time. An *indicates $1.5 \mathrm{mg} / \mathrm{kg}$ MDMA significantly different from placebo $(P<0.05)$. A $\S$ indicates $0.75 \mathrm{mg} / \mathrm{kg}$ MDMA significantly different from placebo $(P<0.05)$. A + indicates $1.5 \mathrm{mg} / \mathrm{kg}$ significantly different from $0.75 \mathrm{mg} / \mathrm{kg}$ MDMA $(P<0.05)$. Bottom panels: Selected scores on subjective ratings following administration of oxytocin or placebo as a function of dose and time. An * indicates $20 \mathrm{IU}$ oxytocin significantly different from placebo $(P<0.05)$. A $\S$ indicates $40 \mathrm{IU}$ oxytocin significantly different from placebo $(P<0.05)$. Error bars represent one SEM. Overlapping error bars were omitted for clarity.

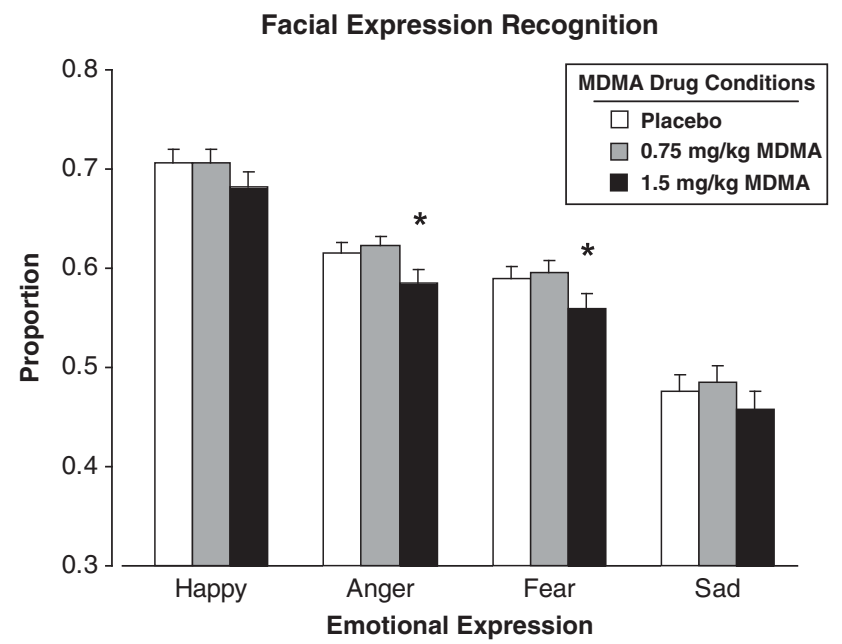

Figure 3 Mean proportion of accurate identification of emotional facial expressions as a function of MDMA dose. An * indicates $1.5 \mathrm{mg} / \mathrm{kg}$ MDMA significantly different from placebo $(P<0.05)$. Error bars represent one SEM.

several additional mood ratings, including 'Insightful' and 'Social'. The current subjective-effects findings are novel, as most previous studies have not reported detectable subjective effects following intranasal oxytocin administra-

\section{Social Choice Task}

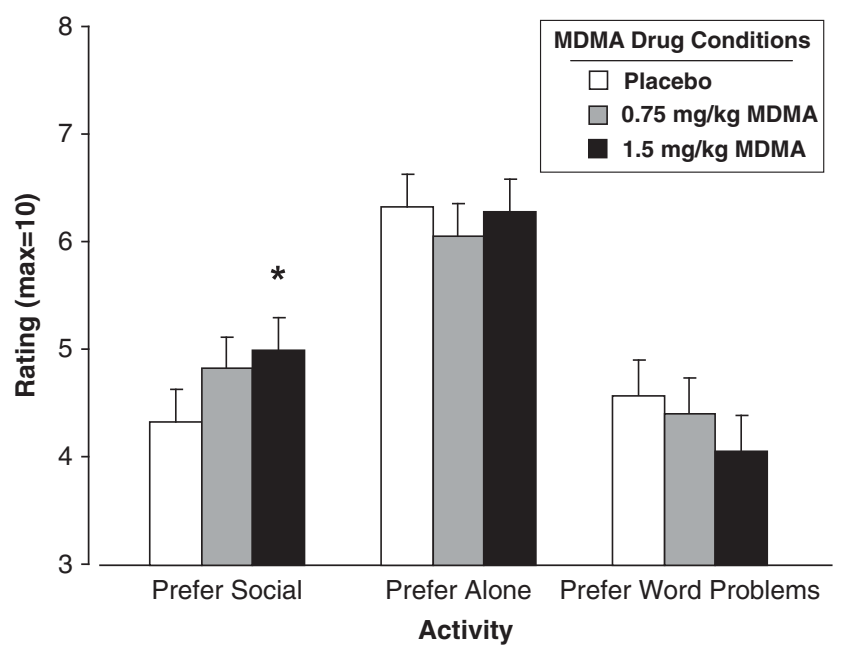

Figure 4 Mean ratings of desire to engage in social and solitary activities as a function of MDMA dose. An* indicates $1.5 \mathrm{mg} / \mathrm{kg}$ MDMA significantly different from placebo $(P<0.05)$. Error bars represent one SEM.

tion (MacDonald et al, 2011). Several features of the design, including the within-subject placebo comparison condition and repeated measures across the time course of the effect may have increased the sensitivity of our procedure, relative 
to previous studies. Interestingly, the finding that the lower oxytocin dose produced greater effects on subjective feelings of sociability is consistent with previous studies indicating that the effects of oxytocin are non-linear. It has been suggested that higher doses of oxytocin may block some if its effects because of increased binding with vasopressin receptors (for a review, see MacDonald and Feifel, 2013). Additionally, we found that oxytocin (40 IU) improved emotion recognition only in women. A previous study reported that oxytocin improves recognition of a range of emotions (Shahrestani et al, 2013) and another study found that the effects of oxytocin on emotional stimuli may differ in women and men (Domes et al, 2010). The full profile of subjective and behavioral effects of oxytocin remains to be determined. Other studies have used further measures of prosocial behaviors, showing that oxytocin increases measures of trust, generosity, and interpersonal communication (Kosfeld et al, 2005; Zak et al, 2007; Ditzen et al, 2009; for review, see MacDonald and MacDonald, 2010), while other researchers have shown that oxytocin can produce antisocial behaviors, such as feelings of envy and mistrust (Bartz et al, 2011a; Declerck et al, 2010; Shamay-Tsoory et al, 2009; for review, see Bartz et al, 2011b). The reasons for the differences are not known, but may include characteristics of the subject samples (eg, age, gender, and hormonal state) or testing environment (eg, outcome measures used, social and physical context of testing). The present findings show that exogenous administration of oxytocin can produce positive mood changes that could facilitate psychosocial function.

At the doses tested here, MDMA and oxytocin did not produce similar effects. For example, for the majority of prosocial subjective-effect items, responses to MDMA were not correlated with responses to intranasal oxytocin, suggesting that the social effects of MDMA are not fully mediated by oxytocin. Clearly, MDMA at these doses produced substantially greater effects than intranasal oxytocin. However, it is likely that the drugs produced different levels of oxytocin in plasma and the brain. Although, both MDMA (Hysek et al, 2012) and intranasal oxytocin (Domes et al, 2010) increase plasma levels of oxytocin, the relative levels are difficult to compare across studies. We have suggestive preliminary data from a separate study that MDMA increased plasma levels of oxytocin to higher levels than intranasal oxytocin, at the doses tested here. Brain levels of the peptide, however, are not known. It is also possible that the effects of oxytocin are more subtle than MDMA effects, and may be influenced by environmental context and individual differences such as sex, behavioral history, and psychiatric conditions (Bartz et al, 2011b).

There were also qualitative differences in the drug effects: MDMA increased heart rate, blood pressure, and subjective feelings of anxiety, whereas oxytocin did not affect cardiovascular measures and the lower dose (20 IU) reduced anxiety. These differences may be attributable to their differing mechanisms of action. MDMA-related effects in the brain are widespread; it potently releases the monoamine neurotransmitters dopamine, serotonin, and norepinephrine in part by inducing carrier-mediated release through their respective transporters (Han and $\mathrm{Gu}, 2006$; Verrico et al, 2007; Rothman et al, 2001), which likely contributes to its wide range of physiological, subjective, and behavioral effects. In rodents, endogenous and exogenous oxytocin binds in brain regions associated with mood, arousal, and reward (Gimpl and Fahrenholz, 2001) and also increases levels of dopamine, serotonin, and norepinephrine (Shahrokh et al, 2010; Vincent and Etgen, 1993; Yoshida et al, 2009). However, in contrast to MDMA, oxytocin modulates release of monoamines via activation of oxytocin receptors (Gimpl and Fahrenholz, 2001), and may have relatively specific and focused neuromodulatory effects on improved information processing in the brain (Owen et al, 2013). Of course, the extent to which intranasal oxytocin acts on specific brain circuits and facilitates neurotransmitter release in humans has yet to be determined.

The present study had several limitations. First, the behavioral measures may not have been obtained at optimal times to detect oxytocin effects. For example, the Social Choice Task was completed $2 \mathrm{~h}$ after the nasal spray, which may have been after the peak effects. However, intranasal vasopressin, a related peptide, increases CSF hormone levels for at least $90 \mathrm{~min}$ (Born et al, 2002) and salivary oxytocin levels remain elevated $7 \mathrm{~h}$ post nasal administration (van Ijzendoorn et al, 2012), suggesting that oxytocin may still have effects $2 \mathrm{~h}$ after administration. Further, in our study the placebo and oxytocin nasal spray formulations differed slightly, raising the possibility that differing sensations may have influenced subject expectations. This seems unlikely to be a major concern, since at the end of the session, participants identified both formulations as placebo equally often (52.3\% for placebo spray; $47.7 \%$ for oxytocin spray). Other potential limitations are the selection of participants (young adult MDMA users, in this case), or the doses of the drugs administered.

In conclusion, MDMA produced a range of prosocial effects: It increased feelings of sociability, increased choice to engage in a social activity, and decreased recognition of anger and sadness in others. This pattern of effects provides further evidence that the drug may be useful in the treatment of PTSD, by facilitating engagement with the therapist and increasing the client's ability to focus on negative emotions (Mithoefer et al, 2013). By contrast, intranasal oxytocin produced small increases in selected ratings of sociability and enhanced negative emotion recognition. Although comparisons between intranasally administered oxytocin and orally administered MDMA are difficult because of differences in dose and route, the present findings suggest that oxytocin is not likely to be the sole mechanism of the prosocial effects of MDMA. It was recently reported sub-threshold doses of either oxytocin or vasopressin and MDMA administered together increased prosocial behavior in rats (Ramos et al, 2013), suggesting an interesting future direction for this research in humans.

\section{FUNDING AND DISCLOSURE}

Dr Kirkpatrick received salary compensation from The University of Chicago. Dr Wardle received salary compensation from The University of Chicago. Dr Jacob received salary compensation from the University of Illinois at Chicago and the University of Minnesota. Dr Lee received salary compensation from The University of Chicago and support from Azevan Pharmaceuticals for travel and data 
presentation for a research project unrelated to this manuscript. Dr de Wit received salary compensation from The University of Chicago and support from Unilever for a research project unrelated to this manuscript.

\section{ACKNOWLEDGEMENTS}

We gratefully acknowledge Jon Solamillo, Celina Joos, Michael Helzer and Charles Frye for technical assistance, Emmanuel Semmes for pharmaceutical support, Gillinder Bedi for contributing to the study design and Matthew Baggott for providing valuable advice on the manuscript. This research was supported by NIH grants DA02812 and DA026570 (PI: Harriet de Wit).

\section{REFERENCES}

Abraham TT, Barnes AJ, Lowe RH, Kolbrich Spargo EA, Milman G, Pirnay SO et al (2009). Urinary MDMA, MDA, HMMA, and HMA excretion following controlled MDMA administration to humans. J Anal Toxicol 33: 439-446.

Bartz J, Simeon D, Hamilton H, Kim S, Crystal S, Braun A et al (2011a). Oxytocin can hinder trust and cooperation in borderline personality disorder. Soc Cogn Affect Neurosci 6: 556-563.

Bartz JA, Zaki J, Bolger N, Ochsner KN (2011b). Social effects of oxytocin in humans: context and person matter. Trends Cogn Sci 15: 301-309.

Bedi G, Hyman D, de Wit H (2010). Is ecstasy an 'empathogen'? Effects of +/-3,4-methylenedioxymethamphetamine on prosocial feelings and identification of emotional states in others. Biol Psychiatry 1134-1140.

Bedi G, Phan KL, Angstadt M, de Wit H (2009). Effects of MDMA on sociability and neural response to social threat and social reward. Psychopharmacology (Berl) 207: 73-83.

Born J, Lange T, Kern W, McGregor GP, Bickel U, Fehm HL (2002). Sniffing neuropeptides: a transnasal approach to the human brain. Nat Neurosci 5: 514-516.

Bos PA, Panksepp J, Bluthe RM, Honk JV (2011). Acute effects of steroid hormones and neuropeptides on human social-emotional behavior: a review of single administration studies. Front Neuroendocrinol 33: 17-35.

Bravo GL (2001). What does MDMA feel like? In: Holland J (ed). Ecstasy: The Complete Guide. A Comprehensive Look at the Risks and Benefits of MDMA. Park Street Press: Rochester, US.

Burkett JP, Young LJ (2012). The behavioral, anatomical and pharmacological parallels between social attachment, love and addiction. Psychopharmacology (Berl) 224: 1-26.

Declerck CH, Boone C, Kiyonari T (2010). Oxytocin and cooperation under conditions of uncertainty: the modulating role of incentives and social information. Horm Behav 57: 368-374.

de Oliveira DC, Zuardi AW, Graeff FG, Queiroz RH, Crippa JA (2012). Anxiolytic-like effect of oxytocin in the simulated public speaking test. J Psychopharmacol 26: 497-504.

Di Simplicio M, Massey-Chase R, Cowen PJ, Harmer CJ (2009). Oxytocin enhances processing of positive versus negative emotional information in healthy male volunteers. J Psychopharmacol 23: 241-248.

Ditzen B, Schaer M, Gabriel B, Bodenmann G, Ehlert U, Heinrichs M (2009). Intranasal oxytocin increases positive communication and reduces cortisol levels during couple conflict. Biol Psychiatry 65: 728-731.

Domes G, Heinrichs M, Glascher J, Buchel C, Braus DF, Herpertz SC (2007a). Oxytocin attenuates amygdala responses to emotional faces regardless of valence. Biol Psychiatry 62: 1187-1190.
Domes G, Heinrichs M, Michel A, Berger C, Herpertz SC (2007b). Oxytocin improves "mind-reading" in humans. Biol Psychiatry 61: 731-733.

Domes G, Lischke A, Berger C, Grossmann A, Hauenstein K, Heinrichs $M$ et al (2010). Effects of intranasal oxytocin on emotional face processing in women. Psychoneuroendocrinology 35: 83-93.

Doty P, de Wit H (1995). Effect of setting on the reinforcing and subjective effects of ethanol in social drinkers. Psychopharmacology (Berl) 118: 19-27.

Dumont GJ, Sweep FC, van der Steen R, Hermsen R, Donders AR, Touw DJ et al (2009). Increased oxytocin concentrations and prosocial feelings in humans after ecstasy (3,4-methylenedioxymethamphetamine) administration. Soc Neurosci 4: 359-366.

Ekman P, Friesen WV (1976). Pictures of Facial Affect. Consulting Psychologists Press: Palo Alto, California.

Fischman MW, Foltin RW (1991). Utility of subjective-effects measurements in assessing abuse liability of drugs in humans. Br J Addict 86: 1563-1570.

Gimpl G, Fahrenholz F (2001). The oxytocin receptor system: structure, function, and regulation. Physiol Rev 81: 629-683.

Han DD, Gu HH (2006). Comparison of the monoamine transporters from human and mouse in their sensitivities to psychostimulant drugs. BMC Pharmacol 6: 6.

Harris DS, Baggott M, Mendelson JH, Mendelson JE, Jones RT (2002). Subjective and hormonal effects of 3,4-methylenedioxymethamphetamine (MDMA) in humans. Psychopharmacology (Berl) 162: 396-405.

Heinrichs M, Baumgartner T, Kirschbaum C, Ehlert U (2003). Social support and oxytocin interact to suppress cortisol and subjective responses to psychosocial stress. Biol Psychiatry 54: 1389-1398.

Higgins ST, Stitzer ML (1988). Time allocation in a concurrent schedule of social interaction and monetary reinforcement: effects of d-amphetamine. Pharmacol Biochem Behav 31: 227-231.

Hysek CM, Domes G, Liechti ME (2012). MDMA enhances 'mind reading' of positive emotions and impairs 'mind reading' of negative emotions. Psychopharmacology (Berl) 222: 293-302.

Hysek CM, Liechti ME (2012). Effects of MDMA alone and after pretreatment with reboxetine, duloxetine, clonidine, carvedilol, and doxazosin on pupillary light reflex. Psychopharmacology (Berl) 224: 363-376.

Jones BT, Jones BC, Thomas AP, Piper J (2003). Alcohol consumption increases attractiveness ratings of opposite-sex faces: a possible third route to risky sex. Addiction 98: 1069-1075.

Justice AJ, De Wit H (2000). Acute effects of d-amphetamine during the early and late follicular phases of the menstrual cycle in women. Pharmacol Biochem Behav 66: 509-515.

Kelly BC, Parsons JT, Wells BE (2006). Prevalence and predictors of club drug use among club-going young adults in New York city. J Urban Health 83: 884-895.

Kirkpatrick MG, de Wit H (2013). In the company of others: social factors alter acute alcohol effects. Psychopharmacology (Berl) 230: $215-226$.

Kirkpatrick MG, Gunderson EW, Johanson CE, Levin FR, Foltin RW, Hart CL (2012). Comparison of intranasal methamphetamine and d-amphetamine self-administration by humans. Addiction 107: 783-791.

Kosfeld M, Heinrichs M, Zak PJ, Fischbacher U, Fehr E (2005). Oxytocin increases trust in humans. Nature 435: 673-676.

Lim MM, Young LJ (2006). Neuropeptidergic regulation of affiliative behavior and social bonding in animals. Horm Behav 50: 506-517.

MacDonald E, Dadds MR, Brennan JL, Williams K, Levy F, Cauchi AJ (2011). A review of safety, side-effects and subjective reactions to intranasal oxytocin in human research. Psychoneuroendocrinology 36: 1114-1126. 
Macdonald K, Feifel D (2013). Helping oxytocin deliver: considerations in the development of oxytocin-based therapeutics for brain disorders. Front Neurosci 7: 35.

Macdonald K, Macdonald TM (2010). The peptide that binds: a systematic review of oxytocin and its prosocial effects in humans. Harv Rev Psychiatry 18: 1-21.

Marsh AA, Yu HH, Pine DS, Blair RJ (2010). Oxytocin improves specific recognition of positive facial expressions. Psychopharmacology (Berl) 209: 225-232.

McGregor IS, Bowen MT (2012). Breaking the loop: oxytocin as a potential treatment for drug addiction. Horm Behav 61: 331-339.

Mithoefer MC, Wagner MT, Mithoefer AT, Jerome L, Martin SF, Yazar-Klosinski B et al (2013). Durability of improvement in post-traumatic stress disorder symptoms and absence of harmful effects or drug dependency after 3,4-methylenedioxymethamphetamine-assisted psychotherapy: a prospective longterm follow-up study. J Psychopharmacol 27: 28-39.

Norman GJ, Cacioppo JT, Morris JS, Malarkey WB, Berntson GG, Devries AC (2011). Oxytocin increases autonomic cardiac control: moderation by loneliness. Biol Psychol 86: 174-180.

Owen SF, Tuncdemir SN, Bader PL, Tirko NN, Fishell G, Tsien RW (2013). Oxytocin enhances hippocampal spike transmission by modulating fast-spiking interneurons. Nature 500: 458-462.

Ramos L, Hicks C, Kevin R, Caminer A, Narlawar R, Kassiou M et al (2013). Acute prosocial effects of oxytocin and vasopressin when given alone or in combination with 3,4-methylenedioxymethamphetamine in rats: involvement of the V1A receptor. Neuropsychopharmacology 38: 2249-2259.

Rodgers J, Buchanan T, Pearson C, Parrott AC, Ling J, Hefferman TM et al (2006). Differential experiences of the psychobiological sequelae of ecstasy use: quantitative and qualitative data from an internet study. J Psychopharmacol 20: 437-446.

Rothman RB, Baumann MH, Dersch CM, Romero DV, Rice KC, Carroll FI et al (2001). Amphetamine-type central nervous system stimulants release norepinephrine more potently than they release dopamine and serotonin. Synapse 39: 32-41.

Shahrestani S, Kemp AH, Guastella AJ (2013). The impact of a single administration of intranasal oxytocin on the recognition of basic emotions in humans: a meta-analysis. Neuropsychopharmacology.

Shahrokh DK, Zhang TY, Diorio J, Gratton A, Meaney MJ (2010). Oxytocin-dopamine interactions mediate variations in maternal behavior in the rat. Endocrinology 151: 2276-2286.
Shamay-Tsoory SG, Fischer M, Dvash J, Harari H, Perach-Bloom N, Levkovitz Y (2009). Intranasal administration of oxytocin increases envy and schadenfreude (gloating). Biol Psychiatry 66: 864-870.

Sumnall HR, Cole JC, Jerome L (2006). The varieties of ecstatic experience: an exploration of the subjective experiences of ecstasy. J Psychopharmacol 20: 670-682.

Tallarida RJ, Murray RB (1981). Manual of Pharmacologic Calculations. Springer: Heidelberg, Germany.

Tancer M, Johanson CE (2003). Reinforcing, subjective, and physiological effects of MDMA in humans: a comparison with d-amphetamine and mCPP. Drug Alcohol Depend 72: 33-44.

Thompson MR, Callaghan PD, Hunt GE, Cornish JL, McGregor IS (2007). A role for oxytocin and 5-HT(1A) receptors in the prosocial effects of 3,4 methylenedioxymethamphetamine ('ecstasy'). Neuroscience 146: 509-514.

van Ijzendoorn $\mathrm{MH}$, Bhandari $\mathrm{R}$, van der Veen $\mathrm{R}$, Grewen $\mathrm{KM}$, Bakermans-Kranenburg MJ (2012). Elevated salivary levels of oxytocin persist more than $7 \mathrm{~h}$ after intranasal administration. Front Neurosci 6: 174.

Verrico CD, Miller GM, Madras BK (2007). MDMA (Ecstasy) and human dopamine, norepinephrine, and serotonin transporters: implications for MDMA-induced neurotoxicity and treatment. Psychopharmacology (Berl) 189: 489-503.

Vincent PA, Etgen AM (1993). Steroid priming promotes oxytocininduced norepinephrine release in the ventromedial hypothalamus of female rats. Brain Res 620: 189-194.

Wardle MC, de Wit H (2012). Effects of amphetamine on reactivity to emotional stimuli. Psychopharmacology (Berl) 220: 143-153.

White TL, Justice AJ, de Wit H (2002). Differential subjective effects of D-amphetamine by gender, hormone levels and menstrual cycle phase. Pharmacol Biochem Behav 73: 729-741.

Yoshida M, Takayanagi Y, Inoue K, Kimura T, Young LJ, Onaka T et al (2009). Evidence that oxytocin exerts anxiolytic effects via oxytocin receptor expressed in serotonergic neurons in mice. $J$ Neurosci 29: 2259-2271.

Young AW, Rowland D, Calder AJ, Etcoff NL, Seth A, Perrett DI (1997). Facial expression megamix: tests of dimensional and category accounts of emotional recognition. Cognition 63: 271-313.

Zak PJ, Stanton AA, Ahmadi S (2007). Oxytocin increases generosity in humans. PLOS ONE 2: e1128.

Supplementary Information accompanies the paper on the Neuropsychopharmacology website (http://www.nature.com/npp) 